\title{
La oportunidad de la restauración de graveras en la recuperación de territorio fluvial: el caso de la gravera de HOLCIM en el río Guadalete
}

\author{
Linares García, L. ${ }^{1}$, José M ${ }^{a}$ Sñanchez García ${ }^{2}$ \\ ${ }^{1}$ Ingeniero de Montes. Director técnico de Linaria Consultores Ambientales S.L.P. \\ C/Amparo Osborne, 35 (11500). El Puerto de Santa María. CÁDIZ (España). \\ ${ }^{2}$ CMAOT, Junta de Andalucía
}

\section{Resumen}

El río Guadalete, con algo más de $160 \mathrm{~km}$ de longitud, es una de las principales arterias riparias de la provincia de Cádiz.

Su cuenca se encuentra muy regulada, con caudales invierno-verano invertidos debido a la laminación de las avenidas invernales por los abundantes embalses y a las sueltas altas para el riego estival. No obstante, se producen inundaciones periódicas que afectan sobre todo a cultivos que se disponen muy cerca de la vegetación de ribera. El territorio fluvial ha disminuido drásticamente en los últimos 60 años.

El tramo medio cuenta con numerosas graveras, de considerable superficie, a la que se le suman motas longitudinales, infraestructuras transversales, etc.

La restauración de graveras (en sentido estricto, "rehabilitación") puede permitir la recuperación del antiguo territorio fluvial. En este caso, se ha llegado a un acuerdo a tres partes entre la administración ambiental, la empresa minera HOLCIM y la comunidad de regantes, cuyos terrenos ocupan en gran medida el antiguo territorio fluvial: la empresa explotadora permuta terrenos con la comunidad de regantes en espacios no inundables y con los sedimentos que taponan actualmente el cauce se acomete la restauración de la gravera.

$\mathrm{Al}$ final, el río recupera territorio fluvial, la empresa minera restaura la gravera, recuperando en este caso el anterior uso agrícola y los agricultores pueden seguir cultivando la tierra.

Palabras clave: DMA, Graveras, Restauración, River widening, Territorio fluvial 


\section{Introducción}

Durante los últimos años el río Guadalete ha modificado drásticamente su estado geomorfológico, de vegetación, de ancho de la lámina de agua, de territorio fluvial disponible, etc. Los cambios se ponen de manifiesto si se compara el estado actual con el que presentaba el río a mitad de siglo pasado, debiéndose los mismos, sobre todo, a la regulación hidrológica de la cuenca, a la concentración agraria e intensificación de la agricultura (uso masivo de fertilizantes, de fitosanitarios, etc.), que ha hecho suyos amplios espacios fluviales, al desarrollo de especies alóctonas invasoras hacia el interior del río, al proceso de incisión y encajonamiento del cauce, etc.

La regulación ha supuesto la disminución en frecuencia e intensidad de las avenidas con caudales generadores de la morfología del cauce; la agricultura ha llegado hasta los márgenes del río, quedando este encorsetado, como si se tratara de un canal, y en general desconectado de su llanura de inundación. Los embalses en cabecera laminan las precipitaciones más abundantes y generosas de la cuenca de otoño y primavera, mientras que se producen sueltas para el riego durante el estío, invirtiendo el régimen de caudales, que llega a ser mayor en verano que en invierno (González del Tánago, 2010.).

Esta regulación ha propiciado una fuerte sedimentación que permite que la vegetación leñosa invada el cauce hacia el interior, disminuyendo así drásticamente la anchura de la lámina de agua. De esta forma se ha incrementado la rugosidad y ante episodios de fuertes precipitaciones, cuando los embalses no son capaces de laminar las avenidas, se producen inundaciones motivadas por la ineficaz capacidad de desagüe del río. A ello contribuye, lógicamente, la escasa pendiente del mismo y el hecho de que se haya perdido una importante parte del territorio fluvial y se haya producido una homogeneización de las unidades geomorfológicas, habiendo desaparecido algunas inherentes al hecho de la existencia del río en si mismo (González del Tánago, 2010.).

Junto a estos aspectos relativos a la agricultura y el manejo del agua han aparecido otra serie de impactos, entre otros los derivados de la extracción de gravas y arenas, el desarrollo de infraestructuras longitudinales y transversales en el Dominio Público hidráulico (DPH), ocupaciones, etc.

Centrando el análisis de la situación en un tramo concreto, durante los últimos años se han realizado una serie de actividades extractivas mineras en el área comprendida en el entorno de Vega de La Florida con el nombre de Bucharaque; en el presente documento se analiza la restauración de Bucharaque, que ha afectado a una superficie aproximada de 59.87 hectáreas. En dicha zona, como se pone de manifiesto más adelante, ha ocurrido lo mencionado en líneas anteriores, habiendo perdido el río una importante superficie de su territorio fluvial de mediados del siglo pasado.

Para evitar cualquier tipo de daño prolongado en el tiempo y con el objeto de restaurar ecológicamente la ribera del Guadalete y geomorfológicamente el conjunto, recuperando también el uso agrícola, Holcim ha cedido una cuantiosa superficie a los 
organismos públicos tratando de recuperar el territorio fluvial que el río tenía en el año 1956 (cuando tan solo existía una presa, Guadalcacín I, de unos $80 \mathrm{hm}^{3}$, frente a los actuales $1500 \mathrm{hm}^{3}$ ) y, sobre todo, otorgando al río unos grados de libertad, el "river widening" de la bibliografía anglosajona (Rohde et al., 2005), que redunden en su mejora ecológica global. Para ello, se presentó y aprobó por la administración competente un nuevo plan de restauración avalado por el organismo ambiental.

\section{Objetivos del nuevo plan de restauración}

Los principales objetivos que establece el plan de restauración:

- Acuerdo entre la consejería de Medio Ambiente, Comunidad de Regantes y Holcim que implica la recuperación de territorio fluvial.

- Determinar los criterios generales y específicos de restauración de las áreas afectadas por la explotación minera.

- Definir la estrategia y líneas de acción en todos aquellos aspectos relativos a la mejora geomorfológica que será precursora de la mejora biológica del río Guadalete y un determinante paso adelante en el cumplimiento de la Directiva Marco del Agua.

- Establecer las bases que sean capaces de compatibilizar los cultivos agrícolas y otras actividades en el entorno del Guadalete con la propia conservación del mismo, dadas las dificultades que conllevaría la recuperación sensu stricto del Dominio Público Hidráulico (D.P.H) por parte de la administración competente.

- Inscripción de los terrenos cedidos por Holcim a nombre de la Administración en el registro de la propiedad y delimitación física sobre el terreno.

\section{Inventario: descripción de la zona de actuación}

\subsection{Estado legal}

La zona de actuación se encuentra en el T.M de Jerez de la Frontera, provincia de Cádiz (Fig. 1).

La gravera, que no afecta a espacios naturales protegidos o áreas con algún tipo de protección, contacta con el río Guadalete en 2500 metros de su margen derecha, donde sí aparecen determinados tipos de Hábitats de Interés Comunitario, concretamente el 92D0 (tarayal) y el 92A0 (alameda). El río Guadalete tiene actualmente Plan Hidrológico en vigor (Real Decreto 1330/2012, de 14 de septiembre, por el que se aprueba el Plan Hidrológico de la Demarcación Hidrográfica del Guadalete y Barbate. Ministerio de Agricultura, Alimentación y Medio Ambiente), que establece el caudal mínimo y los caudales generadores de morfología.

Los estudios hidráulicos confirman que toda la gravera se encuentra en zona de D.P.H (aspecto matizable toda vez que es lógico al encontrarse la gravera unos 3 metros por debajo de la cota original del terreno). 


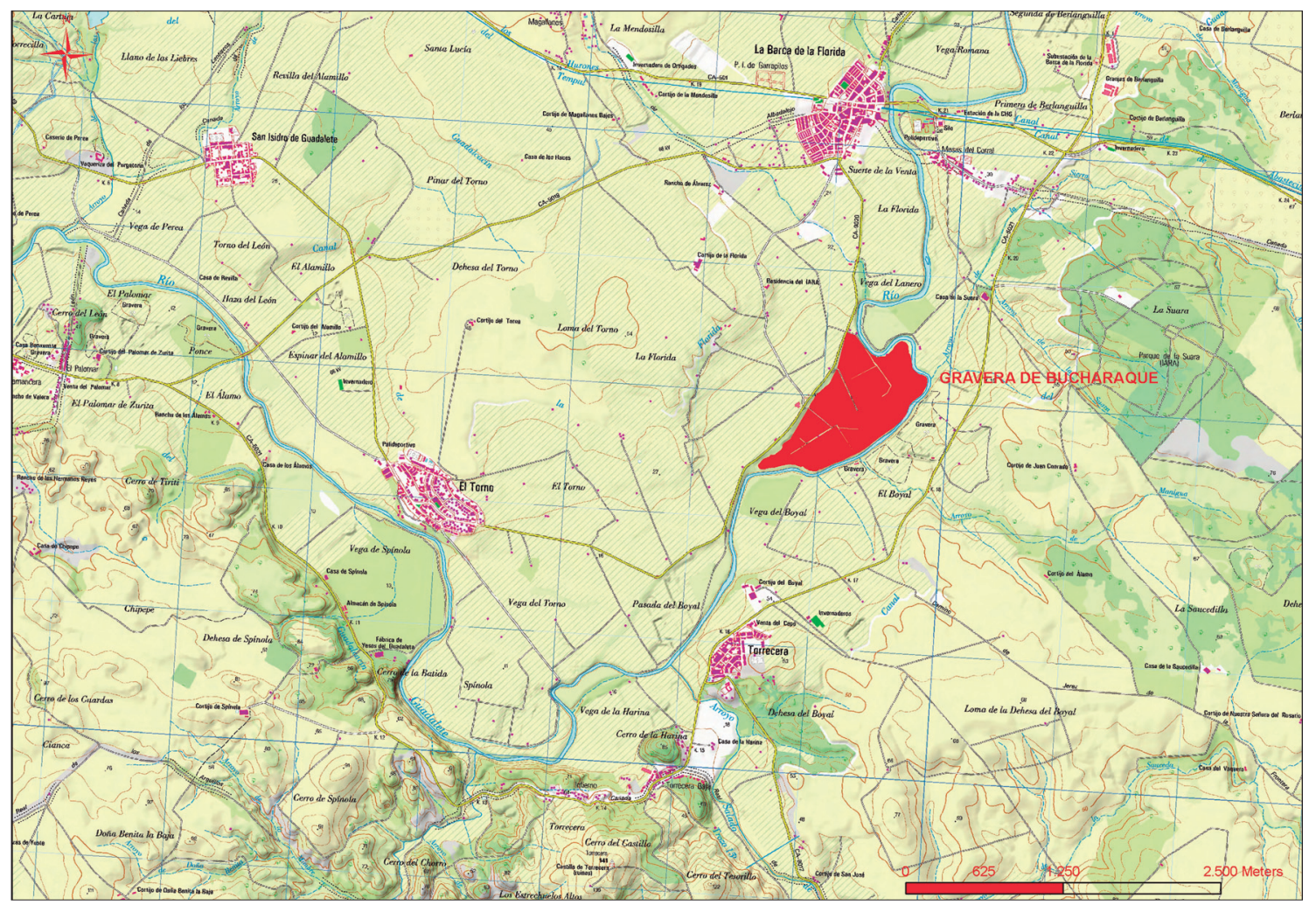

Figura 1. Situación de la gravera de Bucharaque.

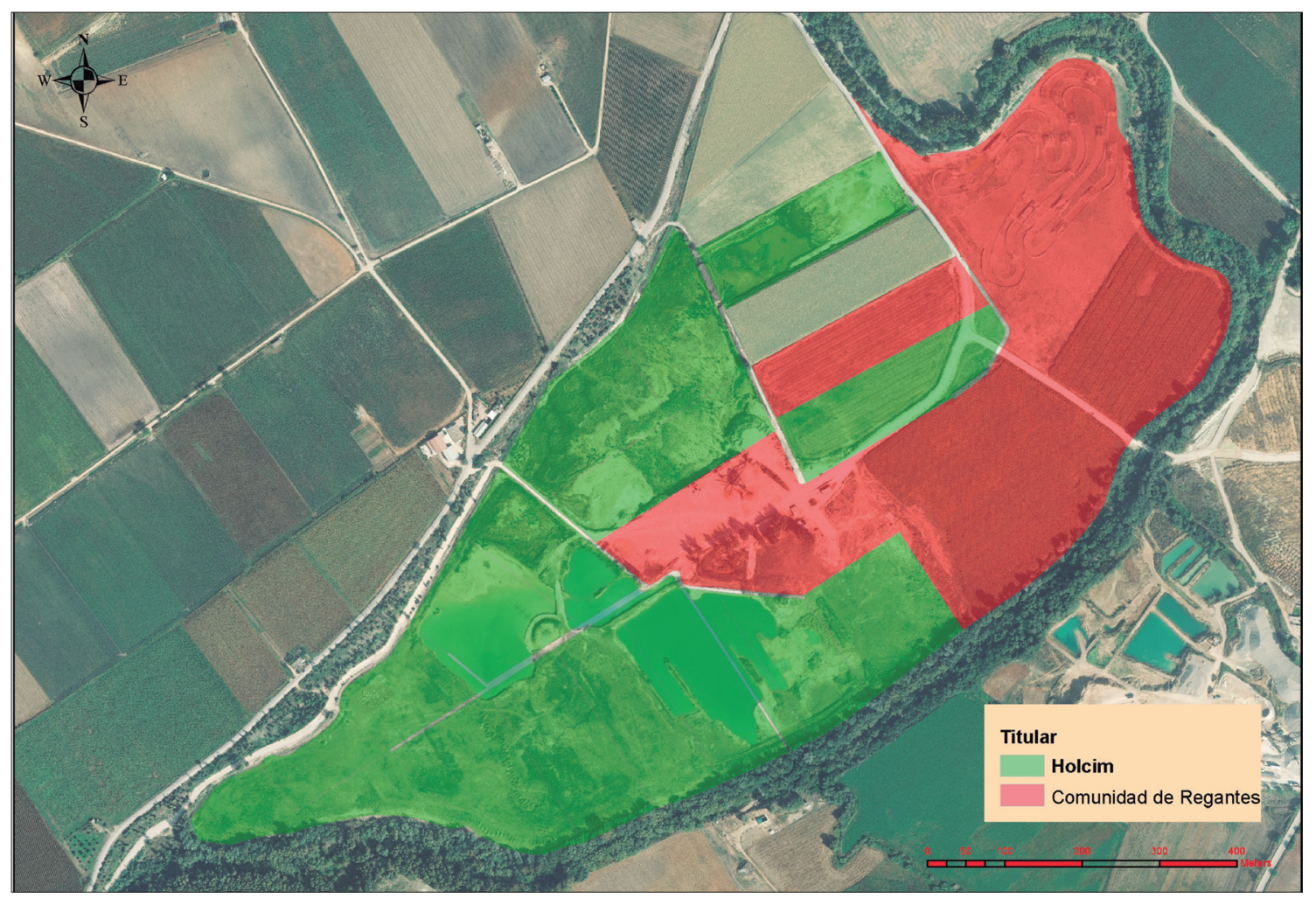

Figura 2. Al noreste, parcelas privadas; al sur y oeste, parcelas de Holcim. 
La gravera tienen un total de 59.87 ha, de las cuales 35.10 ha son de titularidad de Holcim y el resto, 24.77 ha, pertenecen a agricultores privados y a una Comunidad de Bienes de la Barca de la Florida (Fig.2).

\subsection{Estado natural}

Según el Plan Hidrológico del Guadalete-Barbate, el tramo objeto de estudio pertenece a la masa de agua Río Guadalete III - 11904, de naturaleza muy modificada asimilable a río, con una longitud de $67.63 \mathrm{~km}$, con estado peor que bueno.

El incumplimiento con la Directiva Marco del Agua se debe al deterioro de los indicadores biológicos IBMWP e IPS (Ministerio de Medio Aambiente, 2006), al estado fisicoquímico, incumpliendo para amonio y nitratos, para terbutilazina y para el mercurio, y al estado geomorfológico.

Algunos de los aspectos fundamentales ocurridos en la masa de agua Guadalete III desde 1956, actuando sinérgicamente, han sido los siguientes:

- Fuerte disminución de la anchura media de la lámina de agua, que ha pasado de 57 metros en 1956 a tan solo 15 metros actualmente.

- Incremento sustancial de la vegetación densa de ribera (en general con especies exóticas invasoras, fundamentalmente de Eucalyptus camaldulensis), desapare-

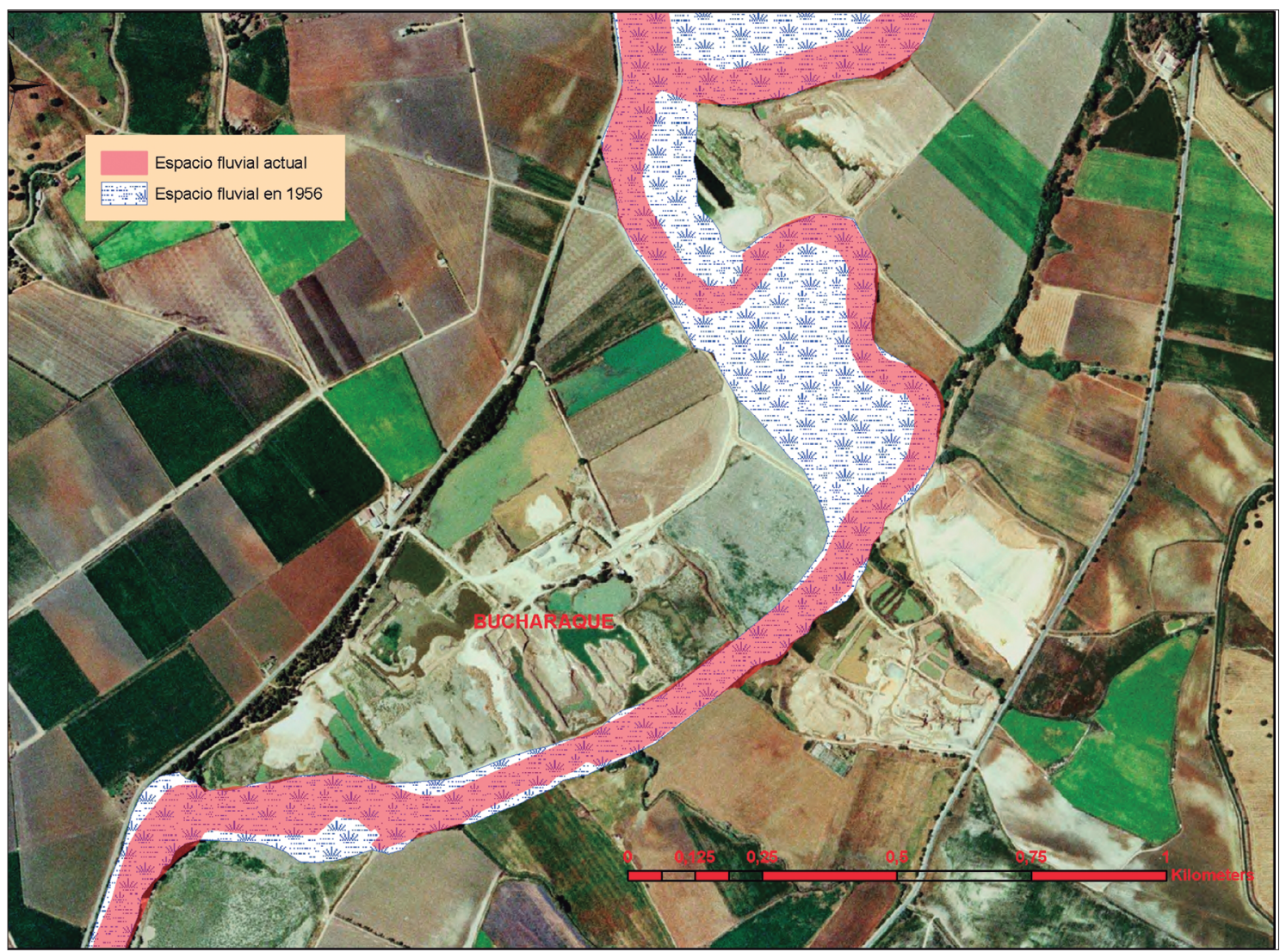

Figura 3. En color más claro, pérdida de territorio fluvial desde 1956. 
ciendo otras unidades morfológicas (barras de sedimentos, herbazales, bosque claro, etc.) que hacen que el río sea precisamente río.

- La agricultura ha ocupado una buena parte de ese territorio fluvial; esa pérdida de territorio fluvial ha sido del 30\% (ha pasado de 884 hectáreas en 1956 a 630 ha en 2013).

- A lo largo de las márgenes existen actualmente numerosas motas (como media, existe un metro lineal de mota por metro lineal de río).

Todas estas circunstancias se han producido también en la zona objeto de actuación, con una pérdida de territorio fluvial de 14.55 ha.

En cuanto a la vegetación, se detecta en las zonas explotadas, deprimidas, una regeneración excelente de taraje (Tamarix sp.) y de álamo blanco (Populus alba), por este orden, si bien unas u otras pueden predominar según la distancia al freático. En la ribera destacan los sauces blancos (Salix alba) junto a la lámina de agua y Popu-

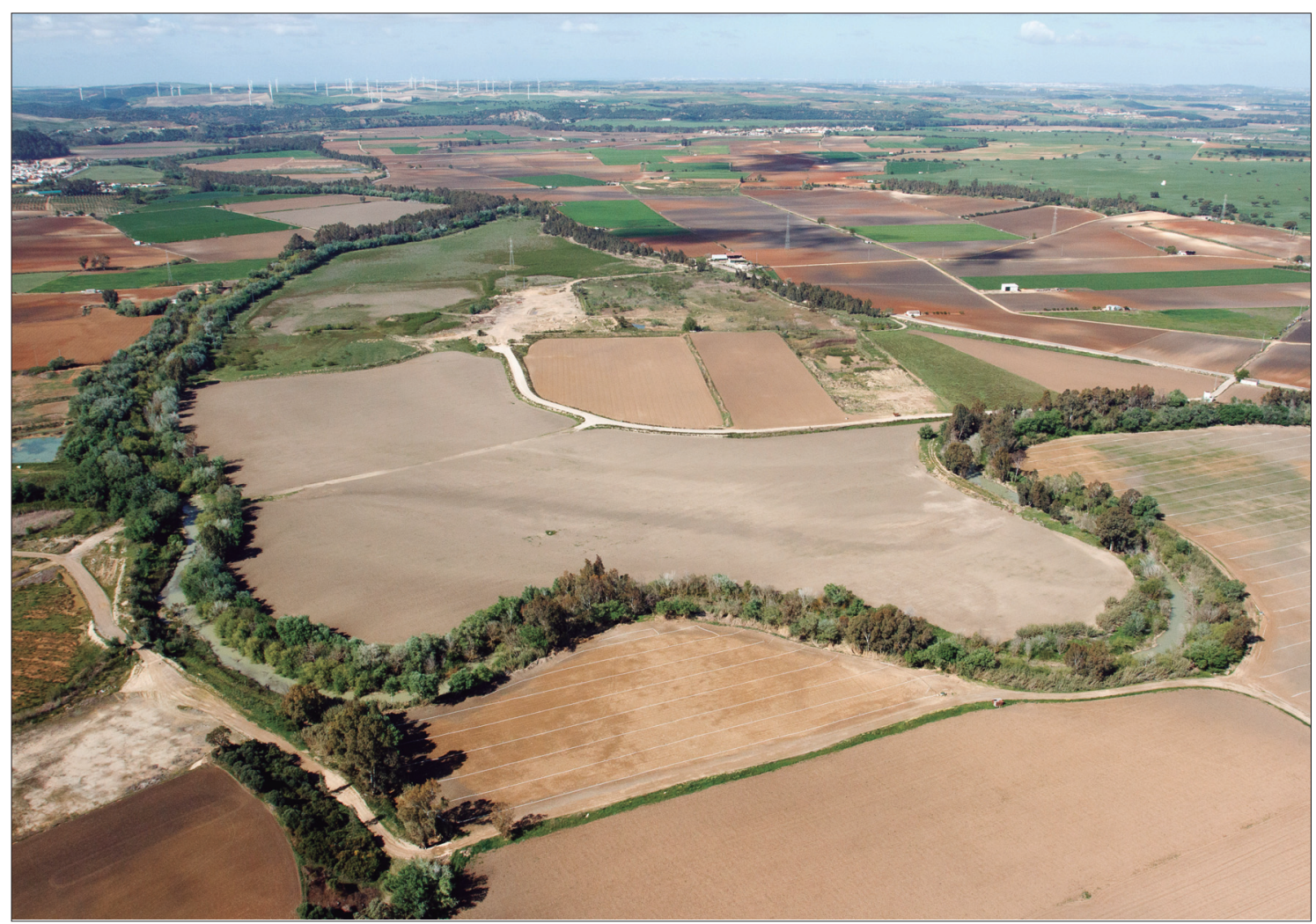

Figura 4. Panorámica general de la gravera desde el noreste.

lus alba en el resto de superficie riebereña; son escasos los tarajes, hay muy pocos eucaliptos (como contraste con otros tramos del Guadalete donde son dominantes) y aparecen puntualmente otras especies ribereñas como el fresno (Fraxinus angustifolia) y el olmo (Ulmus minor). Se observa la presencia puntual de caña (Arundo donax) y también puntual regeneración de eucalipto (Fig. 4). 
En cuanto a la fauna, todas las actuaciones se han realizado teniendo en consideración periodos de nidificación y cría de las abundantes aves.

\subsection{Topografia actual}

Los datos del Modelo digital del Terreno (MDT) del vuelo LiDAR realizado en 2009 se han complementado con el levantamiento topográfico de otros 7000 puntos. Se detecta la presencia de una mota a lo largo de la margen del Guadalete, un estre-

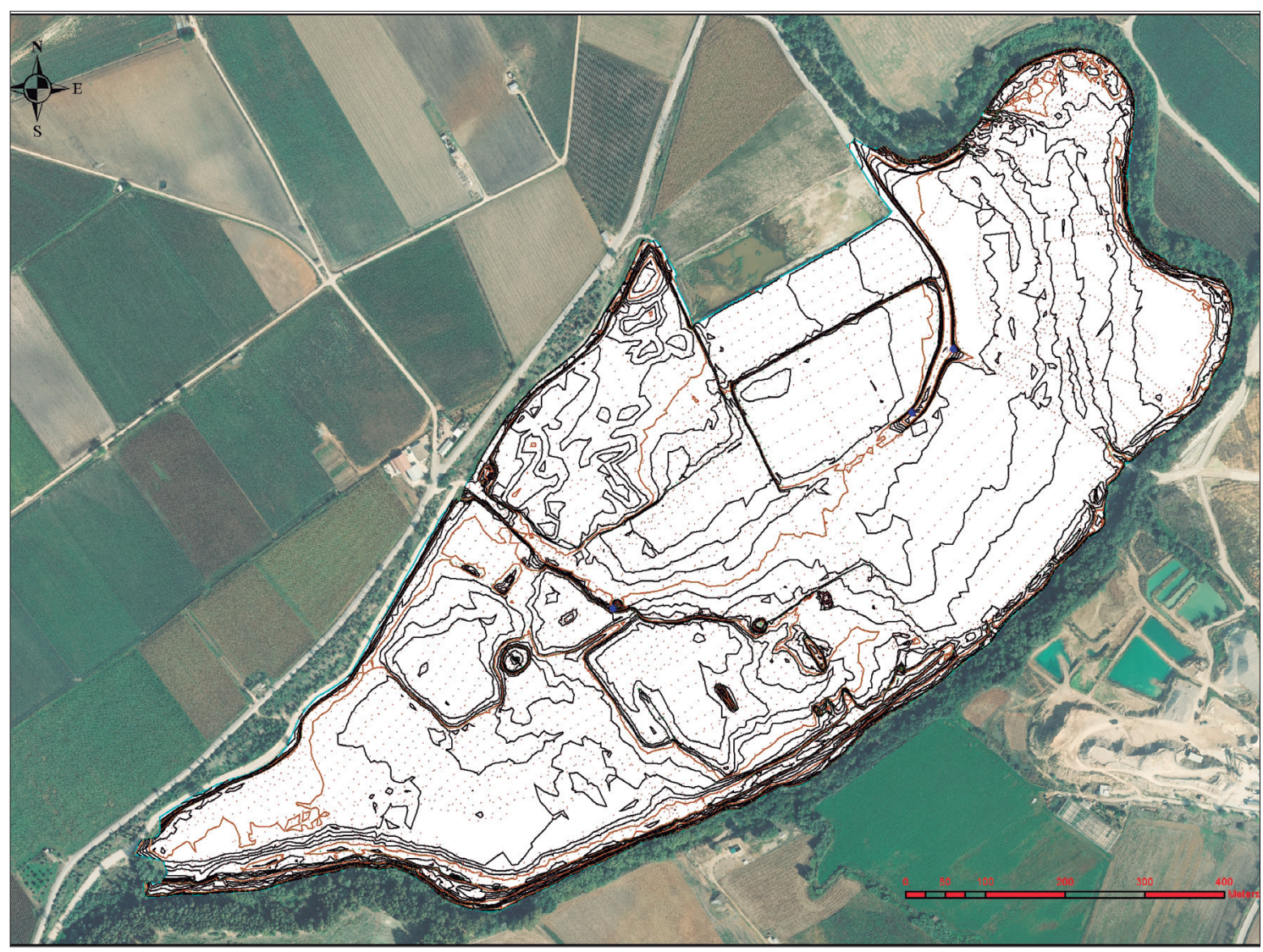

Figura 5. Topografía actual. Al noreste se observa una zona deprimida correspondiente a un antiguo brazo del río. En el resto, se observan los vasos de la gravera.

chamiento o estrangulamiento de la superficie fluvial del río en el límite oeste, donde el río queda constreñido entre la carretera y una gran mota de la margen izquierda, la rotura de la mota en la zona norte y como el río ha recuperado durante la última inundación el antiguo territorio fluvial (entendiendo por tal el correspondiente a 1956). Se observa una gran acumulación de sedimentos en los meandros localizados al noreste (Fig. 5).

El conjunto sirve para obtener una idea muy precisa de las cotas de la gravera, fundamental en la definición de la futura topografía y en el cálculo de remoción de sedimentos. 


\subsection{Análisis de afecciones durante la última inundación}

Se ha comentado que la cuenca está muy regulada: embalses de Zahara, Bornos y Arcos en el Guadalete y Guadalcacín II en el Majaceite, tributario del Guadalete en la Junta de los Ríos, con más de $1500 \mathrm{hm}^{3}$. Sin embargo, periódicamente, ante episodios de elevadas precipitaciones (la sierra de Cádiz recibe en algunos puntos más de $2000 \mathrm{~mm}$ año-1), se produce una merma de la capacidad de laminación de estos embalses, produciéndose inundaciones de amplias superficies con escasa velocidad y lámina de agua variable debido a la escasísima pendiente longitudinal y a la escasa capacidad de desagüe del Guadalete (Fig. 6).

\section{Planificación: propuesta de actuaciones}

\subsection{Propuesta general de restauración}

Con el objeto de conciliar el aprovechamiento sostenido de los recursos hídricos y la agricultura con el cumplimiento de la DMA, se consideran adecuadas actuaciones de eliminación de la vegetación del cauce que permitan posteriores acciones

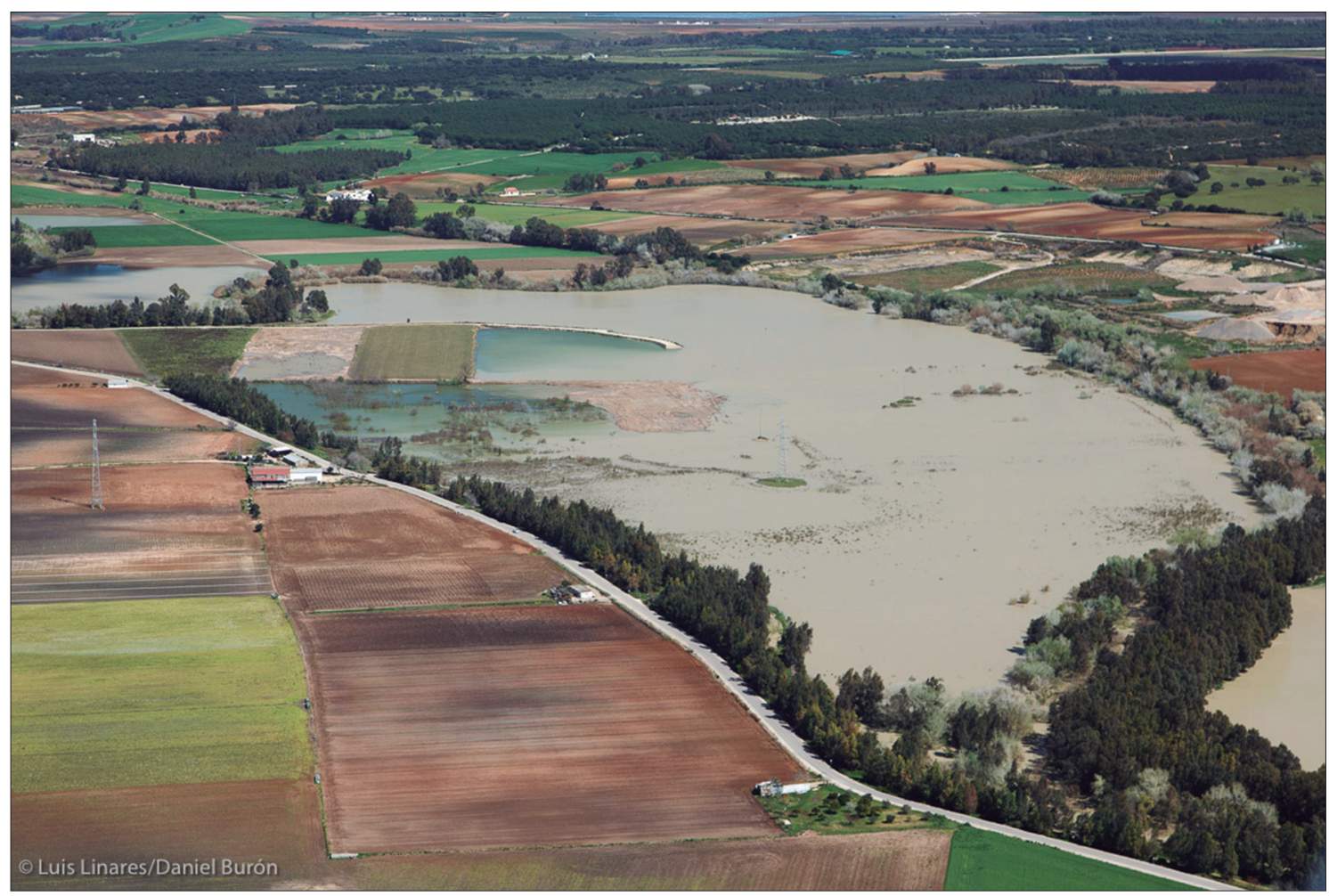

Figura 6. Panorámica desde el suroeste. Junto a la carretera se observa un cordón de eucalipto por fuera del perímetro de la propiedad de Holcim; en la margen derecha del Guadalete, en la zona inferior de la fotografía (izquierda), se observan algunos pies (muy abundantes, sin embargo, en la otra margen, a la derecha de la imagen). 
sobre la morfología de las márgenes similares a las reconocidas en la bibliografía como "river widening": incremento de la sección del cauce eliminando sedimentos, disminución de la pendiente de los taludes del río y recuperación de antiguos brazos del cauce, ganando 14.55 ha de territorio fluvial. Al mismo tiempo se recuperan para el uso agrícola 45.32 ha (Fig. 7).

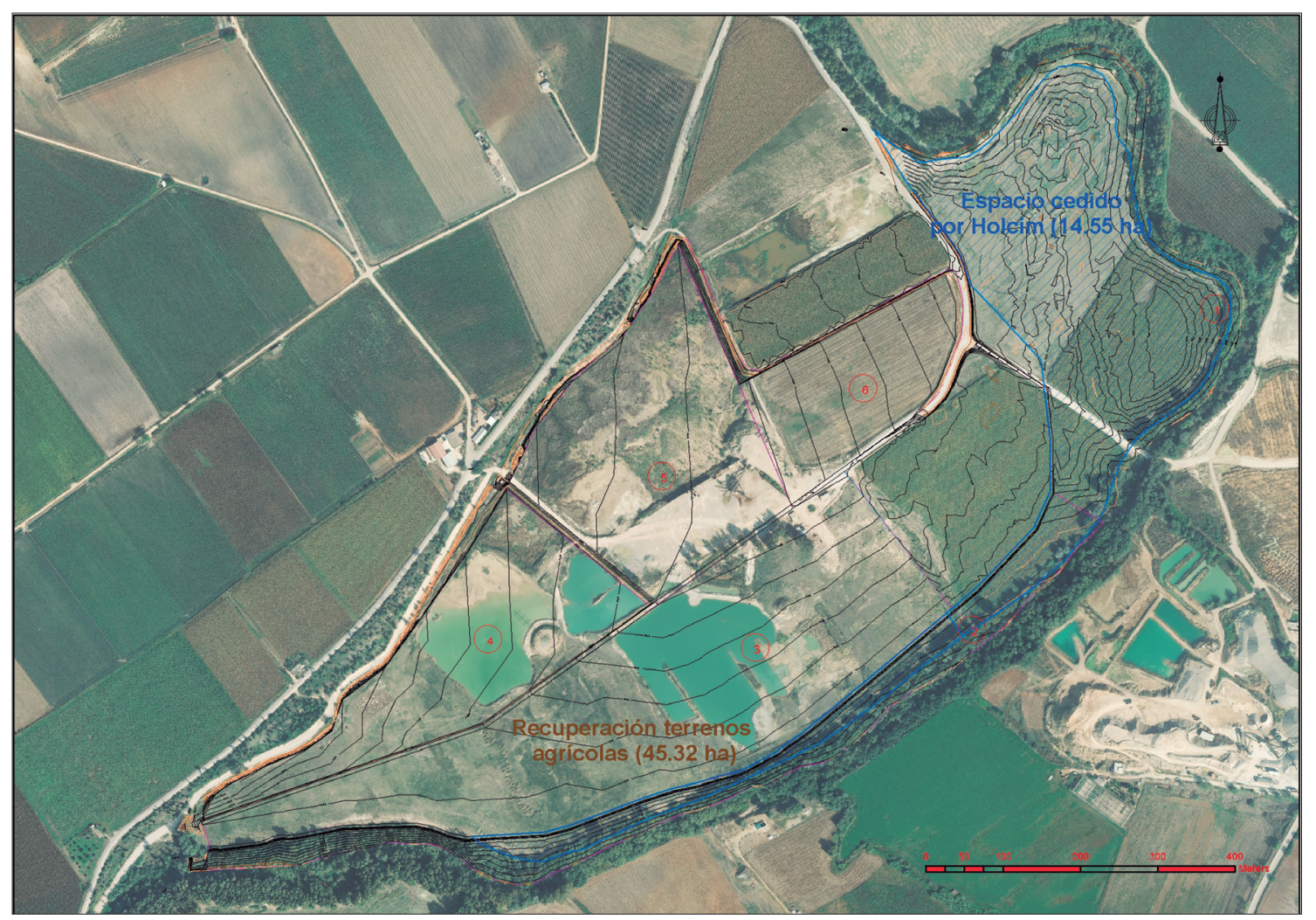

Figura 7. Espacio cedido por Holcim (14.55 ha) y recuperación de terrenos agrícolas (45.32 ha).

\subsection{Propuesta especifica de medidas a adoptar}

\subsubsection{Medidas de recuperación del territorio fluvial: cesión de terrenos por Holcim}

La recuperación de territorio fluvial permitirá la mejora hidromorfológica, la posibilidad de implantación de un régimen adecuado de crecidas contemplado en el Plan Hidrológico Guadalete Barbate (cuando actuaciones similares se hayan desarrollado en otros tramos del río), así como la posibilidad de que se desarrollen bandas protectoras de vegetación más anchas que las actuales, entre otros aspectos. Esto supondrá una disminución de la entrada de sedimentos y de la llegada de nutrientes y fitosanitarios al río, redundando en una mejora directa e indirecta de la calidad de las aguas y de la fauna (ictícola y otras).

Esta recuperación del territorio fluvial no se reparte homogéneamente a lo largo del área de actuación, sino que consiste, como se aprecia en las imágenes, en una banda re- 
lativamente paralela al río en las cotas inferiores y en un amplio espacio de terreno en la zona norte de meandros, donde se recupera un segundo brazo del Guadalete.

En definitiva, siguiendo los criterios de estudios recientes en el río Guadalete (Linares, L. 2012.), se toman las siguientes decisiones:

- Holcim está dispuesta a mejorar el estado geomorfológico del Guadalete (medida precursora de otras mejoras ambientales), cediendo para ello 14.55 hectáreas de sus terrenos de regadío al río.

- Una buena parte de estos terrenos son de titularidad de la Comunidad de Regantes de La Barca, por lo que Holcim adquiere previamente esos terrenos y cede una superficie equivalente a dicha comunidad en vegas colindantes.

- En la zona norte de la gravera la actuación permite la recuperación de un segundo cauce, que coincide con el trazado que toman las aguas en periodos de inundación.

\subsubsection{Actuaciones sobre la morfología y la topografía de la gravera y del río}

\section{Actuaciones sobre el territorio fluvial recuperado y la ribera}

- Eliminar las motas existentes a lo largo de toda la margen, excavando parte de los sedimentos de la margen para obtener nuevos perfiles mucho más abiertos que los actuales, con pendientes menos acusadas que alcanzan los futuros campos de cultivo. A continuación se analiza un perfil/sección concreta.

- Para poder realizar esta actuación se deberá eliminar previamente la vegetación existente en la mota, sobre 4.38 ha. No se afectará a la sauceda junto a la lámina de agua, respetando igualmente los ejemplares singulares de álamo y los escasos fresnos y olmos. Esta actuación, que se localiza en superficies cuya titular es la administración forestal, serán ejecutadas por dicha administración.

- El material del desmonte se utiliza para rellenar la gravera y perfilar adecuadamente los campos de cultivo, con un equilibrio de volúmenes desmonte-terraplén.

- Se eliminarán los sedimentos y residuos existentes en los meandros localizados al norte, que obstruyen el río de forma notable.

- Se recupera un segundo brazo del río ubicado al oeste del cauce actual, por donde discurren las aguas en periodos de avenidas ordinarias.

- En el límite entre las fincas agrícolas y el territorio fluvial consistirá en un desnivel de 1 metro, con un talud de pendiente $1 \mathrm{~V}: 3 \mathrm{H}$ que imposibilite la intrusión por parte de la agricultura, junto con un espacio de uso público a modo de acceso con una anchura de 5 metros. Esto facilita el uso de la zona de servidumbre de paso establecida por la ley al tiempo que facilita el acceso al cauce para futuras actuaciones sin afectar a terceros.

A modo de ejemplo se analiza la situación actual y la propuesta con un perfil tipo. En el esquema se observa la sección actual, cuantificada en metros cuadrados, suponiendo una crecida de las aguas hasta $12.5 \mathrm{~m}$ de cota, y aparece la sección propuesta, que parte desde una cota de actuación cercana a la lámina de agua que sea segu- 
ra para la remoción de los sedimentos y que alcanza en este caso los $11.5 \mathrm{~m}$ de cota. En este punto se ubica un terraplén de $1 \mathrm{~m}$ de altura, con una pendiente $1 \mathrm{~V}: 3 \mathrm{H}$, para alcanzar una cota de 12.5 metros, cota final del terreno agrícola en la línea de contacto con el territorio fluvial propuesto. Se observa que para una subida de las aguas hasta esa cota, la sección pasa de $67.67 \mathrm{~m}^{2}$ a $120.53 \mathrm{~m}^{2}$, es decir, en este punto prácticamente se duplica la capacidad de desagüe (Fig. 8).

\section{Actuaciones sobre el vaso de la gravera}

- Rellenar la gravera hasta la cota especificada en la cartografía, comprendida entre los 10.4-14.60 metros (media de $13.20 \mathrm{~m}$ ), es decir, aproximadamente 3.20 metros por encima de la cota de la lámina más habitual del agua $(9 \mathrm{~m}$ en el punto inferior y 11 en el punto superior de la gravera) y unos 2.6 metros más baja que la cota original del terreno, propiciando las pendientes transversales y longitudinales adecuadas para un eficiente drenaje de las aguas.

- Equlibrio entre el desmonte y el terraplén, con remoción de $200000 \mathrm{~m}^{3}$.

- La restauración adquiere notoriedad también por funcionar como un tanque de tormentas, de eficiencia ya contrastada, cuando el Guadalete alcanza hasta $2 \mathrm{~m}$ por encima de las cotas propuestas.

- Se establece un camino vertebrador central en las zonas agrícolas, de modo que las aguas de escorrentía drenan en parte hacia el Guadalete y en parte hacia un pequeño cauce artificial situado en la zona noroeste.

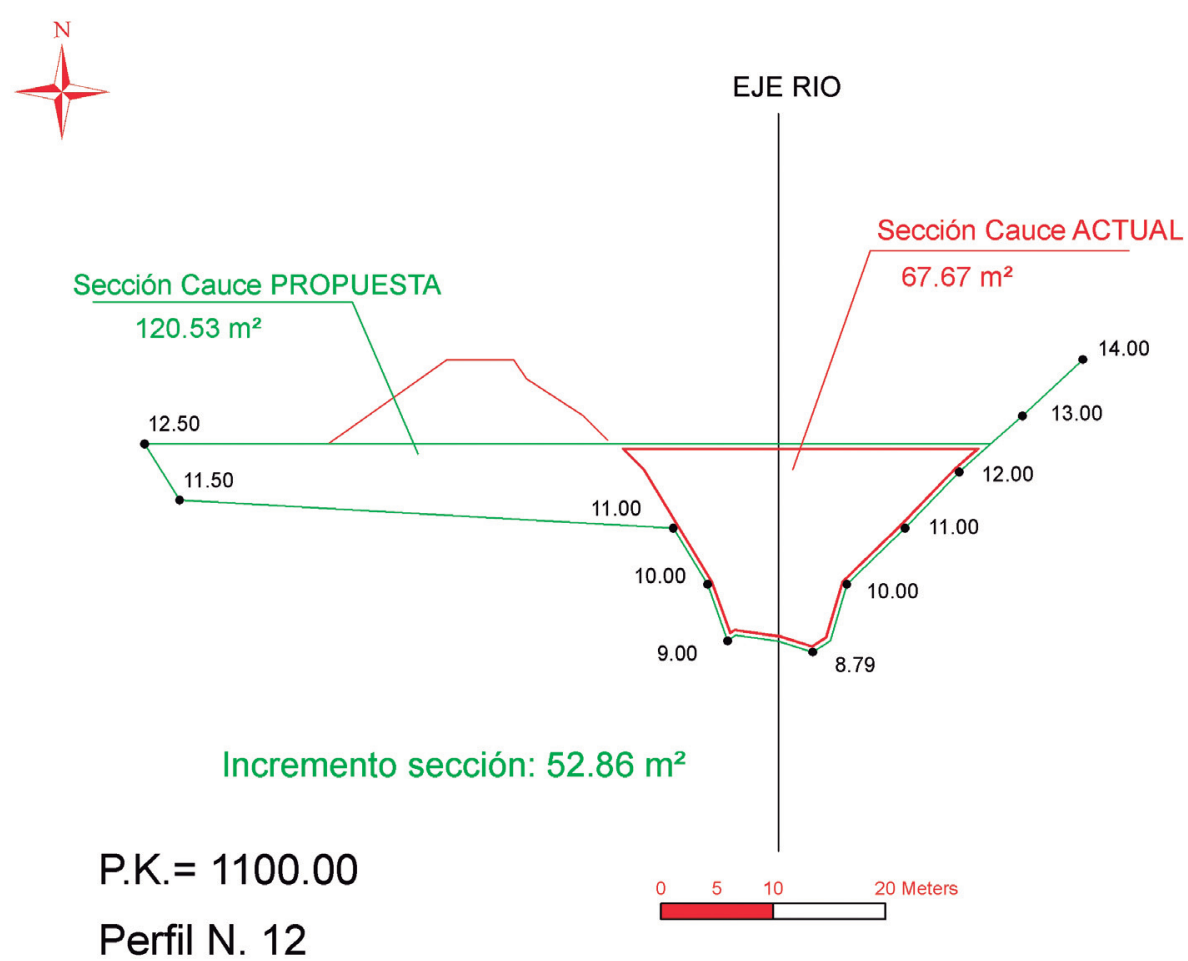

Figura 8. . Perfil transversal. 
- Previamente al relleno, se elimina la abundante vegetación que se ha desarrollado en los vasos de la gravera como consecuencia de las últimas crecidas del río.

\subsubsection{Actuaciones de mejora de la vegetación}

En el Guadalete se ha observado que todas las especies progresan y colonizan con tremenda facilidad cuando se producen las circunstancias apropiadas, sobre todo en relación con el nivel freático; así, Tamarix sp regenera, cabe decir, con excesiva profusión y densidad, evitando el desarrollo de otro tipo de vegetación más desarrollada (la arbórea); algo similar ocurre con Populus alba y en menor medida con Salix alba. Como contrapunto, las condiciones agrícolas de la comarca han propiciado que otras especies características de estos tramos, como el fresno (Fraxinus angustifolia) y el olmo (Ulmus minor), se hallen profundamente deprimidos, hasta el punto de que sólo aparecen puntualmente.

Con estos criterios se consideran adecuadas las siguientes actuaciones:

- En el acceso de uso público de 5 metros se plantará, en el límite más alejado del río, una fila de vegetación con las especies arbóreas Populus alba, Fraxinus angustifolia y Ulmus minor.

- En esa misma longitud, en la parte inferior del desnivel prevista entre el terreno de cultivo y el territorio fluvial se plantarán especies arbóreas potenciales en el área, destacando Fraxinus angustifolia, Ulmus minor y Populus alba. Los objetivos son dos: evitar la posibilidad de intrusismo de los arrendatarios agrícolas y propiciar una adecuada protección de esta "defensa".

- No se plantará en el resto del territorio fluvial recuperado ya que, por un lado, la vegetación autóctona invade ese espacio con rapidez, y por otro, porque se trata otorgar más espacio al río "trasladando la vegetación" desde el propio cauce hacia el exterior.

\section{Conclusiones}

Con las medidas adoptadas se consiguen las siguientes mejoras:

- Se recuperan 14.55 ha de territorio fluvial. Se procederá a la inscripción catastral y registral a nombre la Junta de Andalucía de los terrenos cedidos por Holcim.

- Las actuaciones constituyen en sí mismas el Plan de Restauración de las graveras de Bucharaque.

- Eliminación de motas y de otras infraestructuras antrópicas.

- Mejora de la geomorfología disminuyendo la pendiente de los taludes y recuperando antiguos brazos del río.

- Adaptación a los caudales generadores que especifica el Plan Hidrológico Guadalete-Barbate $\left(263 \mathrm{~m}^{3} \mathrm{~s}^{-1}\right)$ : Mejora geomorfológica del conjunto, dotando al río de grados de libertad ahora inexistentes, con un sustancial incremento de 
la anchura de la lámina de agua que permite un mejor desagüe ante las grandes avenidas o, en su defecto, un menor periodo de inundación tras dichas avenidas.

- La eliminación de parte de la vegetación actual que crece prácticamente en el interior del río y la creación de un cordón vegetal a una mayor distancia del mismo, garantiza una mejora de diversos aspectos cruciales: una menor entrada de sedimentos y una menor entrada de nutrientes y de fitosanitarios, que redundan en una mejora sustancial de la calidad de las aguas.

- Esta mejora de las aguas trae consigo la posibilidad de cumplimiento de aspectos que actualmente se incumplen de la DMA: se mejorarían los indicadores biológicos IBMWP e IPS, que presentan un valor actual moderado, y se mejoraría el estado fisicoquímico, incumplido actualmente para amonio, nitratos, terbutilazina y mercurio.

- En el futuro, cuando las condiciones ecológicas del río mejoren, se podrán realizar repoblaciones o reintroducciones de determinadas especies de fauna

- Se recuperan para el cultivo agrícola de regadío 45,32 hectáreas, satisfaciendo las demandas de las organizaciones agrarias que integran esas superficies de regadío bajo el paraguas de la Política Agraria Común.

\section{Bibliografía}

González del Tánago, M. y col. 2010. Evolución del territorio fluvial del río Guadalete y propuestas para la mejora de su funcionamiento hidro-morfológico. Fundación Conde del Valle de Salazar.

Linares, L. 2012. Elaboración de criterios de actuación para la restauración del río Guadalete. Consejería de Agricultura, Pesca y Medio Ambiente. Junta de Andalucía.

Ministerio de Medio Ambiente. 2006. Orden MAM/3207/2006 por el que se aprueba la ITCMMA EECC-1/06 Instrucción técnica complementaria sobre determinaciones químicas y microbiológicas paea el análisis de las aguas.

Rohde, S; Schütz, M; Kienast, and Englmaier, P. 2005. River widwning: an approach to restoring riparian habitats and plan species. River Res Appl. 21 (1075-1094). 
